\title{
Minimizing the Risks in the Storage of Metallurgical Material
}

\author{
Zdeněk Čujan ${ }^{1,}{ }^{*}$, and Jiř́ Lajtoch ${ }^{2}$ \\ ${ }^{1}$ College of Logistics, Přerov, Palackého 1381/25, 75002 Přerov, Czech Republic \\ ${ }^{2}$ College of Logistics, Prrerov, external doctoral student at the University of Žilina, Faculty of Security \\ Engineering, Univerzitná 1, 01026 Žilina, Slovak Republic
}

\begin{abstract}
The paper focuses on minimizing the risks in the storage of metallurgical material in a specific company which needs to cope with a limited space for material storage in general. At present, the metallurgical material, together with other purchased items, is stored in a designated space in the production hall, from which it is directly distributed to the production. The aim of the solution is to propose a more efficient use of the designated storage space while increasing the safety of work and minimizing occupational injuries.
\end{abstract}

\section{Introduction}

Storage is an integral part of logistics that involves a fairly wide range of problem areas [1]. It serves as an important link between manufacturers and customers [2, 3]. Closely related topics include stock levels, order cycles, warehouse equipment, warehouse zoning, spatial layout and inventory management [4]. Storage also fulfils several important functions: receiving and storing stock items, creating or improving their utility value and performing the necessary warehousing operations.

\section{Current state analysis}

The storage facility for metallurgical material is the largest storage space in the company [5]. It is closed, located directly in the production hall and serves for supplying the material to the production [6]. Besides metallurgical material, other materials such as plastics, nonferrous metals, aluminium and stainless steel materials are stored in the storage facility. The metallurgical material has various profile shapes of different cross-sections (square, rectangular, round, tubular). The supplied length is usually $6 \mathrm{~m}$.

The storage facility is operated by a total of nine employees, including seven operators and two technicians. As for the technological equipment, the facility belongs into the category of mechanized warehouses. In addition to hand manipulation with the material using handling trolleys there are three forklift trucks and two cranes used (one is operated from the ground, the other, which is a bridge crane, is operated from a cabin) [7].

"Corresponding author: zdenek.cujan@,vslg.cz 
The total area of the storage facility is $1,174 \mathrm{~m}^{2}$, the usable area is $712 \mathrm{~m}^{2}$. The difference between the total area and the usable area, which is $712 \mathrm{~m}^{2}$, is used relatively inefficiently as a handling area.

There are a total of six universal racks and one cantilever rack. The material is stored both vertically and horizontally. The cranes are used to stow the material on the cantilever rack.

Purchased materials are usually stored in lengths of $3 \mathrm{~m}$, except for steel profile material, which is stored in lengths of $6 \mathrm{~m}$.

\section{Storage systems for metallurgical material}

A survey of suppliers offering storage systems for metallurgical material provided a useful overview of solutions which may improve the layout of the storage facility in the given company. This section provides a list of selected products:

\section{Suppliers of cantilever racks}

BEG Bohemia spol. s r. o.

The products offered by the company include: pallet racks (drive-in, cable reel, gravity), shelf racks, mobile racks (shelf, pallet, cantilever), cantilever rack, steel mezzanines (heavy mezzanines, steel platforms, warehouse extensions) and other systems [8].

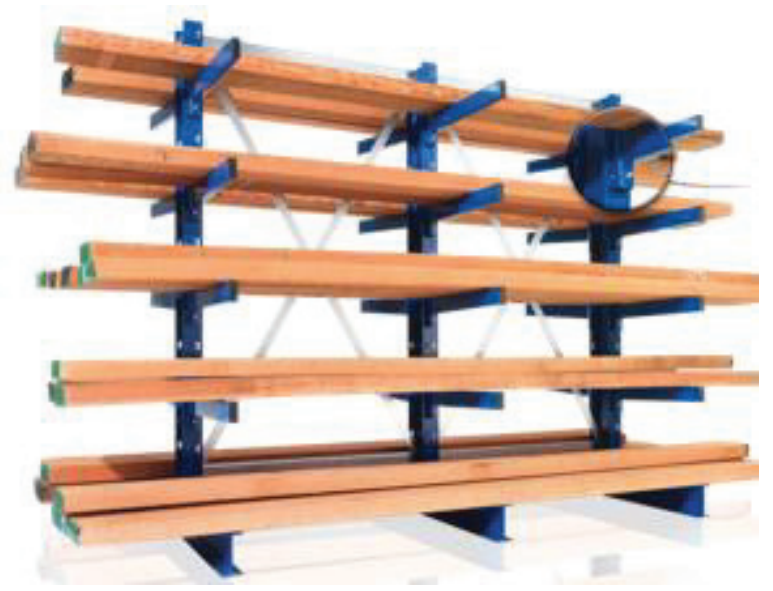

Fig. 1.Cantilever rack Multistong. Source: BEG Bohemia spol. s r. o. Source: [9]

BITO skladovacítechnika CZ s.r.o.

The product range of the company is very wide. It offers various storage systems (several kinds of bins and containers), gravity racking systems for non-palletised loads (shelving, multi-tier installations, mezzanines, automated small parts storage), pallet racking systems (pallet racking, mobile, automated, gravity, drive-in systems), container transport, workshop equipment and storage systems for long loads (cantilever racking) [10]. 


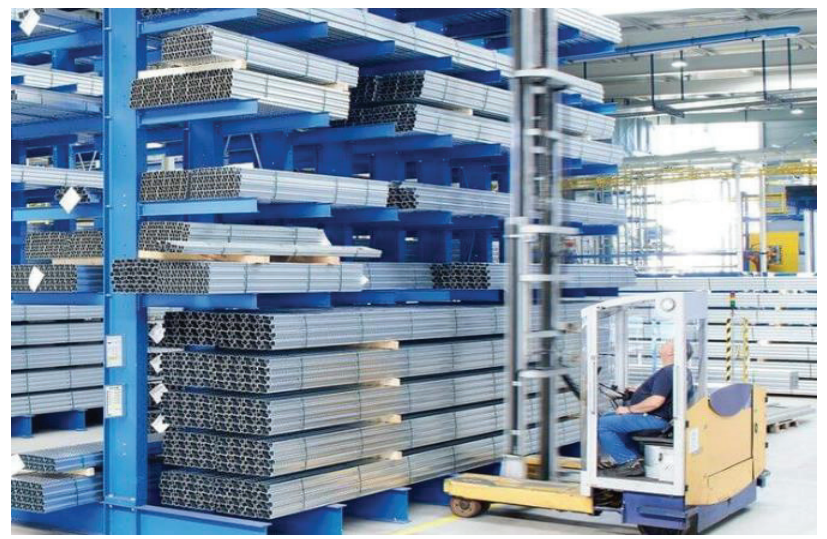

Fig. 2. BITO cantilever racking. Source: BITO s. r. o. Source: [7]

KREDIT spol. sr.o.

The most used is the UNIKANT cantilever racking, which is primarily intended for storing board or rod-shaped metallurgical material, sheet metal, etc. The material is stowed on the rack girders by handling equipment or by hand individually, as bundles, or other handling units. It is always placed on two or more girders of the same storage level of the rack. Racks are intended for stowing by forklift trucks, special loading machines or cranes with accessories [10].

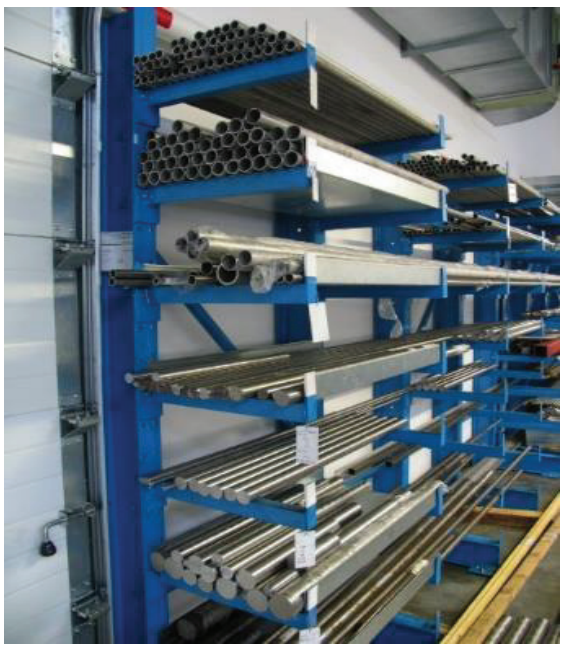

Fig. 3. UNIKAT cantilever racking. Source: [7]

KASTO Maschinenbau, GmbH

In addition to conventional storage systems such as racks, floor storage and stacking cradles, the company offers the UNITOWER system which has several advantages in terms of space requirements and speed of access to individual items. The storage system can be both single-sided and double-sided. The UNITOWER system features a sliding platform located longitudinally or transversely in the tower system[7]. 


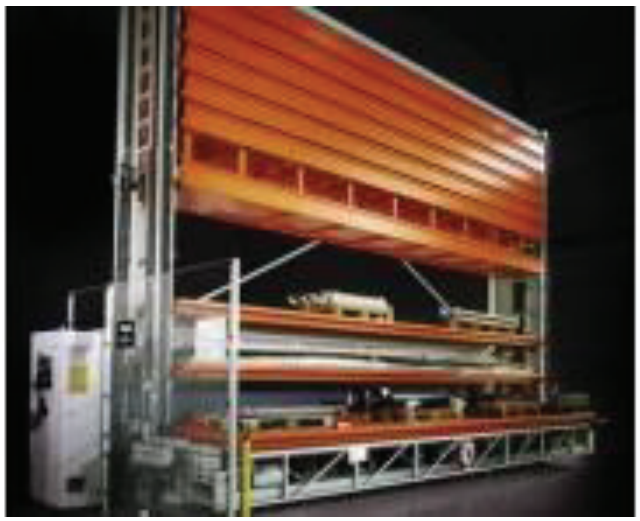

Fig. 4. UNITOWER storage system. Source: [7]

KARDEX s. r. o.

One of the systems supplied by Kardex for the storage of oversized and heavy material is the Towermat vertical lift system. Its design makes it suitable for fitting to a given space and for storing long profile materials, sheets or pallets [7].

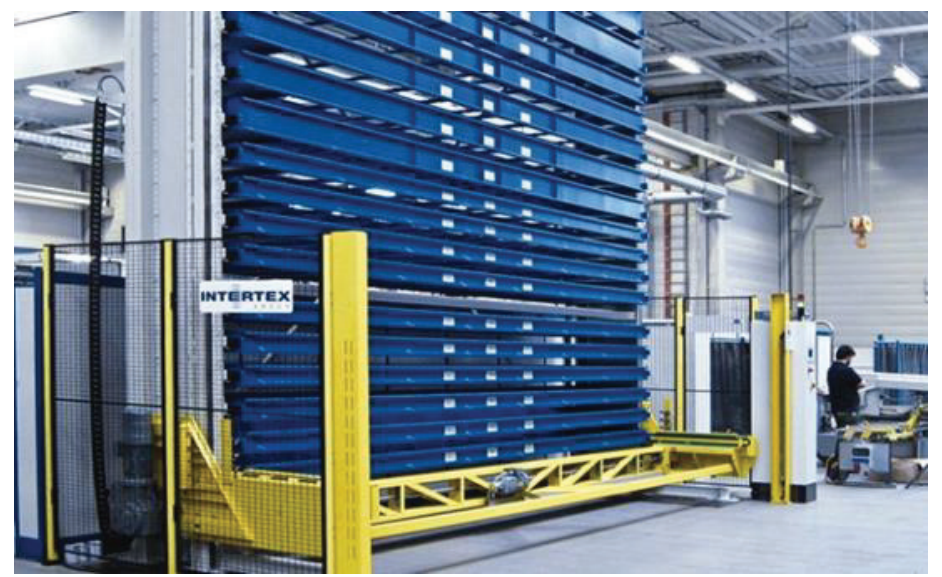

Fig. 5. Towermat automated storage system. Source: [7]

The Towermat system enables efficient material storage up to a total weight of 5,000 kg per tray.

\section{Design of a more efficient layout of the storage facility}

In order to design a more efficient layout of the storage facility, the following requirements were established after consulting the company management:

- maximizing storage space using vertical storage,

- optimizing shelf layout based on size so that shorter or residual material can be stored in longer shelves as well,

- minimal load bearing capacity of one shelf $1,000 \mathrm{~kg}$,

- $\quad$ rack height $7 \mathrm{~m}$,

- shelf width 3 to $6 \mathrm{~m}$,

- maximal diameter of stored material at least $270 \mathrm{~mm}$,

- storing material in the handling direction, 
- using semi-automated or fully automated system,

- minimizing necessary operator presence,

- minimizing the number of operators [1].

These requirements were processed into a request for quotation which was sent to selected suppliers of storage systems.

Based on the subsequent analysis, the LS (LongSpan) Tower storage system supplied by KREDIT was chosen for storing all profile material.

Compared to similar systems provided by other companies, LS Tower offers greater usable depth of its storage shelves and its load bearing capacity is greater by $1,0 \mathrm{~kg}$. It also has 13 shelves more than other comparable systems. This particular storage system is able to store metallurgical material with a total weight of up to $58,0 \mathrm{~kg}$.

It will replace the two universal racks which are currently located at the front of the storage facility. Free usable area will be created which can be used as a central section where the material is received. In addition, the system will also replace racks located in the middle part of the storage area where $19,000 \mathrm{~kg}$ of material is stored and provide storage capacity for $21,0 \mathrm{~kg}$ of material which is currently stored on the floor [10].

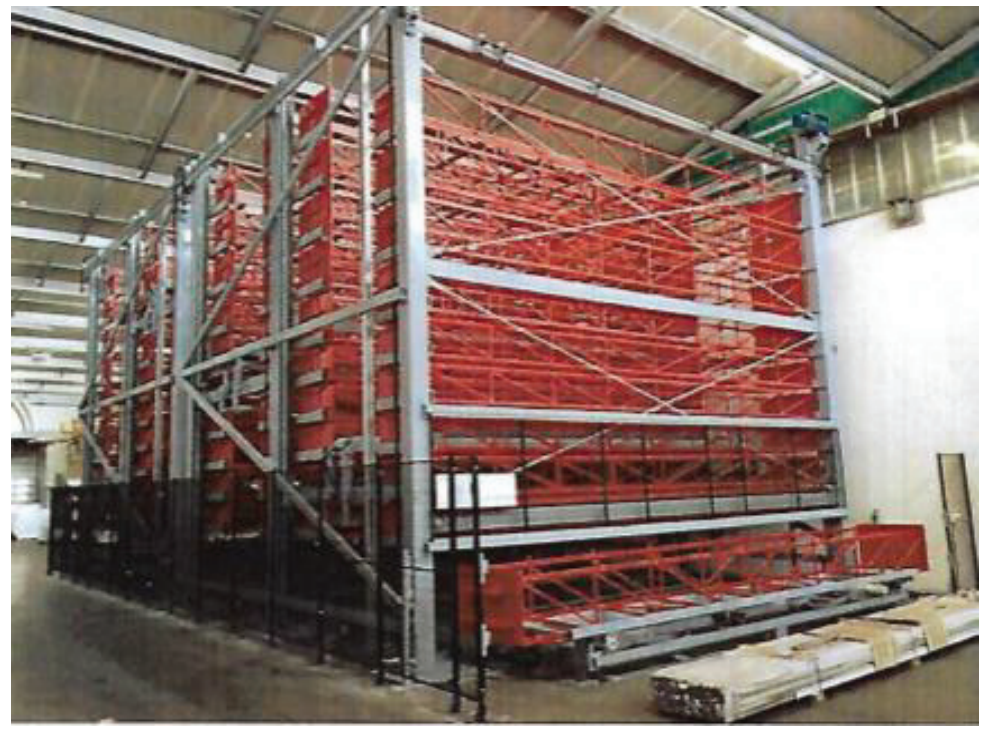

Fig.6. LS Tower automated vertical storage system. Source: [10]

Using the proposed LS Tower vertical automated storage system, the original storage racks can be replaced obtaining more free space of $198 \mathrm{~m}^{2}$ in the storage facility which can be efficiently used for storing material on the floor, as a handling area, etc.

\section{Evaluation of the proposed solution}

To evaluate the proposed solution, logistics indicators of its economy and logistics indicators of its productivity were used. 


\subsection{Logistics indicators of the proposed solution economy}

Using the indicators of economy, the level of the logistics systems efficiency will be determined before and after the implementation of the proposed LS Tower vertical automatic storage system.

- Indicator of equipment costs per operator:

$$
K=\frac{E_{m}}{Z_{m}}
$$

where: $E_{m}$ is the sum of all the purchase costs of the handling equipment in the evaluated logistics system; $Z_{m}$ is the number of operators employed in the evaluated logistics system for material handling.

Indicator of equipment costs after the implementation of the new storage system:

$$
\begin{aligned}
& K=\frac{2,822,650}{9} \\
& K=313,628 C Z K
\end{aligned}
$$

The calculation shows that the equipment costs per operator after the implementation of the new storage system will be 313,628 CZK per operator.

\subsection{Logistics indicators of the proposed solution productivity}

Using the indicators of productivity, the level of the logistics systems efficiency will be determined before and after the implementation of the proposed LS Tower vertical automatic storage system.

- Indicator of usable storage area:

Indicator of usable storage area before the implementation of the new storage system:

$$
K_{s}=\frac{S}{S_{c}} \cdot 100[\%]
$$

where: $S$ is the area used for storing the material $\left[\mathrm{m}^{2}\right] ; S_{c} \quad$ is the total area of the storage facility $\left[\mathrm{m}^{2}\right]$.

Indicator of equipment costs after the implementation of the new storage system:

$$
\begin{gathered}
K_{s}=\frac{712}{1,174} \cdot 100 \\
K_{s}=60.6 \%
\end{gathered}
$$

Indicator of usable storage area after the implementation of the new storage system:

$$
K_{s}=\frac{514}{1,174} \cdot 100[\%]
$$




$$
K_{s}=43.8 \%
$$

The implementation of the new storage system will save $17 \%$ of the storage area.

- Indicator of material picking:

Indicator of material picking before the implementation of the new storage system:

$$
\begin{aligned}
& V_{p}=20 \mathrm{~min}(33 \%) \\
& M_{n}=130 C Z K / \text { hour } \\
& C_{n}=V_{p} \cdot M_{n} \\
& C_{n 1}=\frac{33 \cdot 130}{100} \\
& C_{n 1}=43 C Z K
\end{aligned}
$$

where: $V_{p}$ is the time of picking one item requested for production; $M_{n}$ is the labour costs per operator; $C_{n 1}$ is the total costs.

Indicator of material picking after the implementation of the new storage system:

$$
\begin{aligned}
& V_{p}=15 \min (24.75 \%) \\
& M_{n}=130 C Z K / \text { hour } \\
& C_{n}=V_{p} \cdot M_{n} \\
& C_{n 2}=\frac{24.75 \cdot 130}{100} \\
& C_{n_{2}}=32 C Z K
\end{aligned}
$$

The calculation shows that the implementation of the new automated storage system will save $11 \mathrm{CZK}$ per picking one requested item.

- Indicator of financial savings:

Indicator of financial savings before and after the implementation of the new storage system:

$V_{p}=8249 /$ year 2016

$$
\begin{gathered}
C_{n 1}=43 C Z K \\
C_{n 2}=32 C Z K \\
U_{m n 1}=V_{p} \cdot C_{n 1} \\
U_{m n 2}=V_{p} \cdot C_{n 2} \\
U_{m n}=U_{m n 1}-U_{m n 2}
\end{gathered}
$$


where: $V_{p}$ is the time of picking one item requested for production per year; $C_{n l}$ is the total costs before the implementation; $C_{n 2}$ is the total costs after the implementation; $U_{m n 1}$ is the labour costs savings before the implementation; $U_{m n 2}$ is the labour costs savings after the implementation.

$$
\begin{gathered}
U_{m n 1}=8249.43=354,707 \mathrm{CZK} / \text { year } \\
U_{m n 2}=8249.32=263,968 \mathrm{CZK} / \text { year } \\
U_{m n}=354,707-263,986=90,739 \mathrm{CZK} / \text { year }
\end{gathered}
$$

The evaluation shows that the total financial savings are 90,739 CZK.

\section{Conclusion}

Most companies aim to use their storage facilities more effectively. This holds for the storage of metallurgical material as well. Unsuitable storage racks, which cannot accommodate larger quantities of material, and low to zero identification of stored items these are the most common shortcomings that lead not only to time losses but also to increased administration demands and hence to greater error rates [10].

These risks can be reduced by the implementation of automated storage systems which also increase safety, productivity and business competitiveness.

This paper is supported by the research project "From horse-drawn railway to intermodal transport" within Visegrad Fund.

\section{References}

1. Z. Cujan, Open Engineering 6, 470-475 (2016)

2. G. Fedorko, N. Husáková, G. Dudáš, Acta Montanistica Slovaca 15, 14-22 (2010)

3. V. Molnar, K. Pacutova, in Proceedings of the third international conference on traffic and transport engineering (ICTTE), 570-575 (Belgrade, Serbia, 2016)

4. J. Fabianova, P. Kacmary, V. Molnar, P. Michalik, Open Engineering 6, 270-279 (2016)

5. N. Husakova, G. Fedorko, V. Molnar, S. Honus, in Ecology, economics, education and legislation conference proceedings, SGEM 2016, II, 187-194 (2016)

6. H. Neradilova, G. Fedorko, Open Engineering 6, 700-710 (2016)

7. B. Martináková, Skladování hutního materiálu (Přerov, Czech Republic, 2017)

8. R. Rohan, Hutní Materiál (Prague, Czech Republic, 1987)

9. BEG Bohemia, Available online: http://www.beg-regaly.cz/en (2017)

10. Z. Čujan, Z. Málek, Výrobni a obchodni Logistika (Zlín, Czech Republic, 2008) 